\title{
Photonic Ultra-Wideband 781.25-Mb/s Signal Generation and Transmission Incorporating Digital Signal Processing Detection
}

\author{
Gibbon, Timothy Braidwood; Yu, Xianbin; Tafur Monroy, Idelfonso
}

Published in:

I E E E Photonics Technology Letters

Link to article, DOI:

10.1109/LPT.2009.2022503

Publication date:

2009

Document Version

Publisher's PDF, also known as Version of record

Link back to DTU Orbit

Citation (APA):

Gibbon, T. B., Yu, X., \& Tafur Monroy, I. (2009). Photonic Ultra-Wideband 781.25-Mb/s Signal Generation and Transmission Incorporating Digital Signal Processing Detection. I E E E Photonics Technology Letters, 21(15), 1060-1062. https://doi.org/10.1109/LPT.2009.2022503

\section{General rights}

Copyright and moral rights for the publications made accessible in the public portal are retained by the authors and/or other copyright owners and it is a condition of accessing publications that users recognise and abide by the legal requirements associated with these rights.

- Users may download and print one copy of any publication from the public portal for the purpose of private study or research.

- You may not further distribute the material or use it for any profit-making activity or commercial gain

- You may freely distribute the URL identifying the publication in the public portal 


\title{
Photonic Ultra-Wideband 781.25-Mb/s Signal Generation and Transmission Incorporating Digital Signal Processing Detection
}

\author{
Timothy Braidwood Gibbon, Xianbin Yu, and Idelfonso Tafur Monroy
}

\begin{abstract}
The generation of photonic ultra-wideband (UWB) impulse signals using an uncooled distributed-feedback laser is proposed. For the first time, we experimentally demonstrate bit-for-bit digital signal processing (DSP) bit-error-rate measurements for transmission of a 781.25-Mb/s photonic UWB signal over fiber links. The DSP algorithm is described, the generated UWB signal is shown to comply with the U.S. Federal Communications Commission requirements, and transmission of $1.71 \times 10^{5} \mathrm{UWB}$ bits over fiber is demonstrated without error.
\end{abstract}

Index Terms-Bit-error rate (BER), digital signal processing (DSP), photonic signal generation, ultra-wideband (UWB) signals.

\section{INTRODUCTION}

$\mathbf{U}$ LTRA-WIDEBAND (UWB) radio is a rapidly emerging technology with widespread applications including wireless detectors, radar, and high-speed wireless short-range communication [1]. Low-power UWB radio telecommunication signals that satisfy the U.S. Federal Communications Commission (FCC) requirement of being below $-41.3 \mathrm{dBm} / \mathrm{MHz}$ from 3.1 to $10.6 \mathrm{GHz}$ can, however, only propagate over distances of $10-15 \mathrm{~m}$. Photonic UWB signal generation is thus extremely useful for extending UWB reach by fiber transmission, which facilitates efficient control and distribution of UWB signals from a central office. Complex UWB photonic signal generation equipment can thus be localized at the central office, while simple antennas placed within the home can be used to distribute wireless UWB signals to devices such as high-definition televisions containing digital signal processing (DSP) receiver chips.

Previous methods of photonic UWB signal generation can be separated into two broad categories. The first category uses a time delay, where two Gaussian pulses with $\pi$ phase difference are combined at the receiver side by controlling the delay time between them [2]. Various implementations of optical delay lines have been utilized including fiber Bragg grating (FBG) [3]-[5], differential group delay modules [6], and dispersive media [7]. The second category exploits the nonlinear processing capabilities of some electrical and photonic

Manuscript received January 21, 2009; revised March 30, 2009. First published May 12, 2009; current version published July 15, 2009.

The authors are with the DTU Fotonik-Department of Photonics Engineering, Technical University of Denmark, DK-2800 Kgs. Lygnby, Denmark (e-mail: tbgi@fotonik.dtu.dk).

Color versions of one or more of the figures in this letter are available online at http://ieeexplore.iee.org.

Digital Object Identifier 10.1109/LPT.2009.2022503 components, after which the derivative of a Gaussian pulse is achieved. For example, use of a microwave differentiator [8], nonlinear pulse shaping of FBG [9], and nonlinear modulation of electrooptical modulators [10], [11] have been proposed. In addition, a photonic UWB generator based on the direct current modulation of a laser and chirp-to-intensity conversion has also been experimentally demonstrated [12].

In this letter, we use a simple and flexible approach to generate an FCC-compliant 781.25-Mb/s UWB optical signal by exploiting the carrier dynamics response of an uncooled distributed-feedback (DFB) laser. The proposed scheme avoids the complexity of mode-locked lasers, custom FBGs, spectral shaping components, and nonlinear elements as in many of the previously reported optical UWB generation techniques. Our UWB signal is transmitted over single-mode fiber (SMF) links, after which the bit-error rate (BER) is determined using DSP in a bit-for-bit comparison between the transmitted and received signals [13]. To the best of our knowledge, this is the first time that DSP has been implemented in this manner for UWB BER measurements.

\section{EXPERIMENT SETUP AND OPERATION PRINCIPLE}

The experimental setup is shown in Fig. 1(a). A 1553.6-nm external cavity laser (ECL) intensity modulated at $12.5 \mathrm{~Gb} / \mathrm{s}$ is injected into an uncooled 1551.4-nm DFB laser, which is used as the transmission wavelength. A $0.38 \mathrm{~nm}$ full-width at half-maximum (FWHM) bandpass filter positioned after the circulator is used to remove the ECL wavelength and suppress the erbium-doped fiber amplifier (EDFA) noise. The UWB pulse is subsequently transmitted through an optical fiber link and detected by a photodiode (PD) with a $12-\mathrm{GHz} 3-\mathrm{dB}$ bandwidth. The electrical spectrum is then measured and compared to the FCC requirement mask, and the BER is determined using an Agilent 40-GSa/s digital storage oscilloscope and the DSP algorithm described in Section IV.

Fig. 1(b) shows the optical spectra directly after the circulator, as well as the transfer function of the filter used to reject the 1553.6-nm ECL wavelength. The ECL wavelength is chosen to correspond to a secondary DFB lasing mode, thereby ensuring cross-gain modulation transfer to the 1551.4-nm DFB transmission wavelength.

\section{Generation of Optical UWB Pulse}

The shape of the UWB pulse in the time domain and the corresponding electrical spectra depend on the carrier response dynamics of the DFB laser, the modulation pattern, and the 
(a)
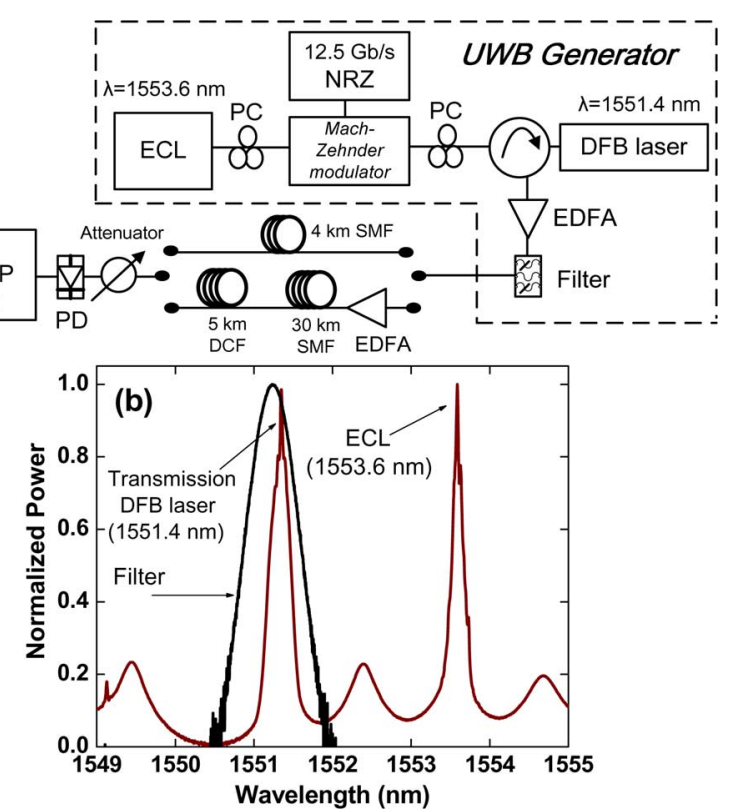

Fig. 1. (a) Experimental setup used to generate photonic UWB signals. (b) Optical spectra of the DFB laser used for transmission and the ECL laser used to introduce cross-gain modulation.

pulsewidth of the external injection signal. Cross-gain modulation in the DFB laser is resulted due to the injection of the intensity modulated signal from the MZM, which causes the carrier and photon density inside the DFB laser active region to change with time, accompanied by relaxation oscillations which results in a complex UWB pulse shape. A sequence of 16 bits modulated at $12.5 \mathrm{~Gb} / \mathrm{s}$ is used to generate a single UWB bit, at an effective bit rate of $781.25 \mathrm{Mb} / \mathrm{s}$. A "1" UWB bit consists of the 12.5-Gb/s 16-bit sequence "1010 000000000000 ". A "0" UWB bit consists of a sequence of 16 consecutive " 0 " $12.5 \mathrm{~Gb} / \mathrm{s} \mathrm{bs}$. The UWB pulses in the time and electrical domains are shown in Fig. 2 for three cases: back-to-back, after transmission over $4 \mathrm{~km}$ of SMF, and after transmission over $30 \mathrm{~km}$ of SMF with $5 \mathrm{~km}$ of matching dispersion-compensation fiber (DCF).

From the electrical spectra of Fig. 2(b), it is evident that the corresponding back-to-back UWB pulse of Fig. 2(a) meets the FCC requirements from 3.1 to $10.6 \mathrm{GHz}$. The -10 -dB fractional bandwidth about the central frequency of $6.3 \mathrm{GHz}$ is around $60 \%$. A comparison between Fig. 2(a), (c), and (e) confirms that transmission does not significantly alter the pulse shape, and in each case, the electrical spectrum complies with the corresponding FCC mask between 3.1 and $10.6 \mathrm{GHz}$. In Section IV, we describe the DSP detection algorithm and present BER results for transmission of the UWB signal over fiber links.

\section{DSP ALGORITHM AND BER RESULTS}

Fig. 3 shows the back-to-back signal received by the 40-GSa/s digital storage oscilloscope $\left(I_{\mathrm{REC}}\right)$ at an optical input power of $-12.0 \mathrm{dBm}$ for a $100110 \mathrm{UWB}$ bit sequence. Also shown is
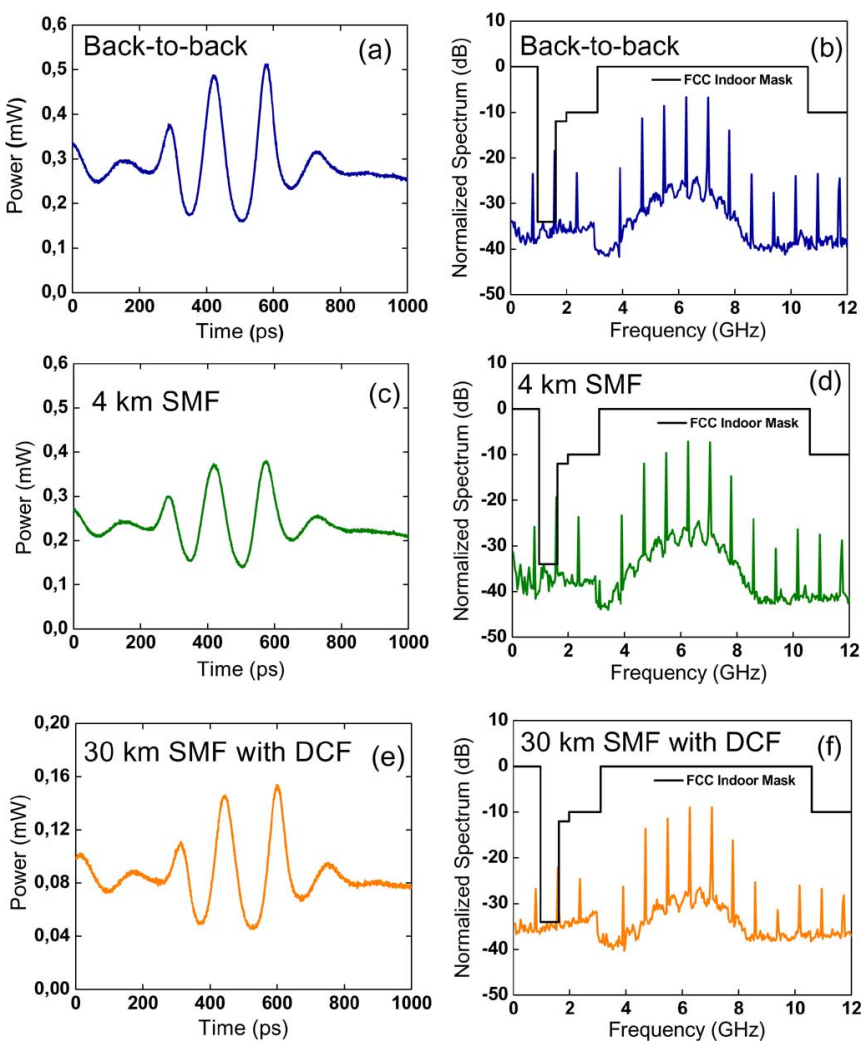

Fig. 2. (a), (c), (e) Single UWB pulses at the DFB wavelength, before and after transmission over SMF. (b), (d), (f) The corresponding electrical spectra relative to the normalized FCC mask.

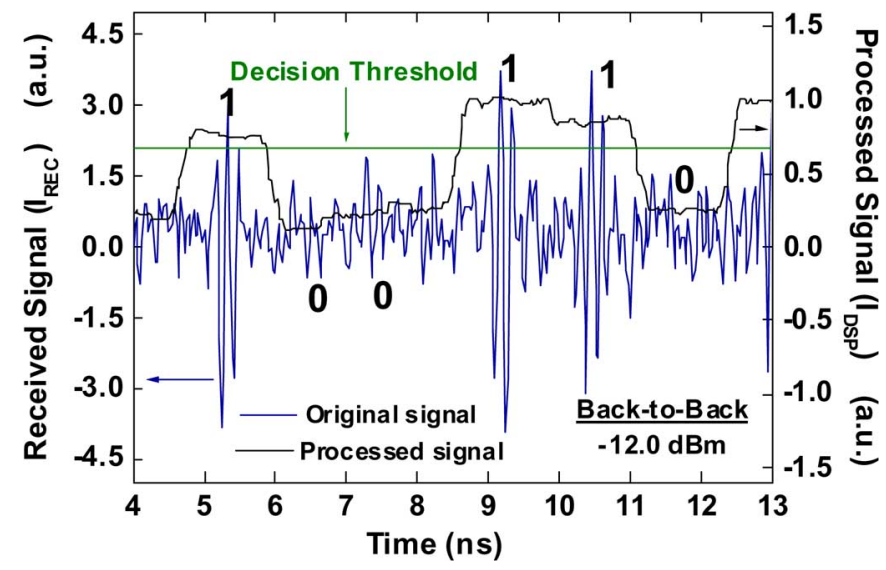

Fig. 3. DSP processed and received signals as captured by the $40-\mathrm{GSa} / \mathrm{s} \mathrm{digital}$ storage oscilloscope.

the processed DSP signal $\left(I_{\mathrm{DSP}}\right)$, which is generated offline in accordance with

$$
I_{\mathrm{DSP}}(t)=\int_{\tau=t-(T / 2)}^{\tau=t+(T / 2)} \frac{I_{\mathrm{REC}}(\tau)^{2}}{T} d t
$$

where $T=1.28 \mathrm{~ns}$ is the UWB bit period corresponding to a bit rate of $781.25 \mathrm{Mb} / \mathrm{s}$. The processed DSP signal is thus effectively the running average of the squared received signal over a bit period. The optimum decision threshold and clock 


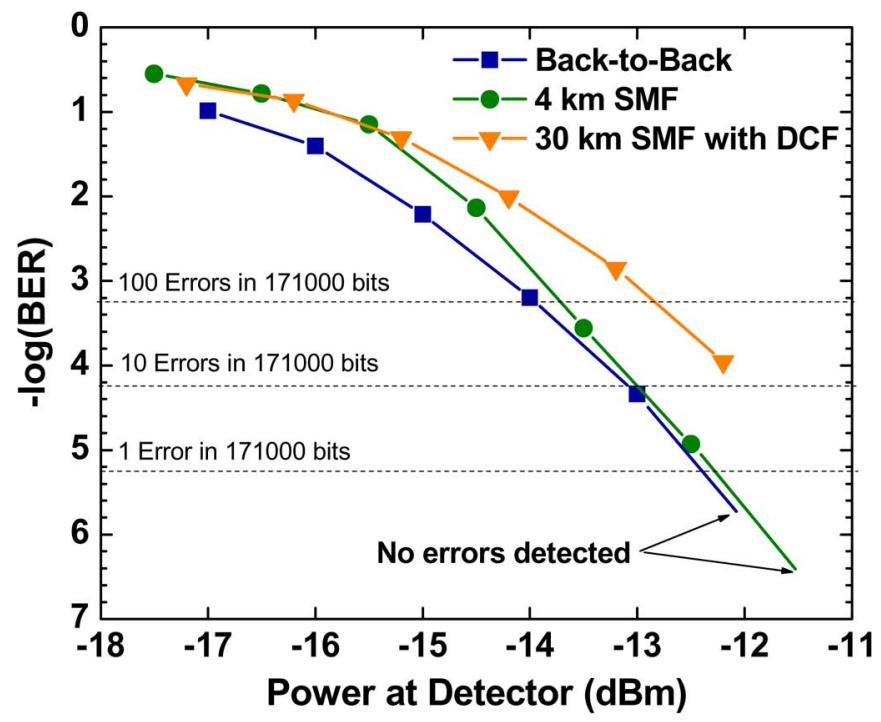

Fig. 4. BER curves obtained using the DSP algorithm in a bit-for-bit comparison between the transmitted and received signals.

recovery timing is chosen using a dithering approach so as to minimize the BER. The average of $I_{\mathrm{DSP}}$ within each bit slot is then compared to the decision threshold. If the average of $I_{\mathrm{DSP}}$ is greater than the decision threshold, then the bit is assigned a logical " 1 " value, and visa-versa for a logical "0" value.

Fig. 4 shows the BER results for $781.25-\mathrm{Mb} / \mathrm{s}$ UWB signal transmission. For each BER measurement point, $1.71 \times 10^{5}$ UWB bits following a $2^{7}-1$ PRBS pattern are transmitted and recorded using the 40-GSa/s digital storage oscilloscope. The BER is subsequently computed using the DSP algorithm in a bit-for-bit comparison between the transmitted and received bits. This approach is expected to provide more accurate results than BER estimates from the eye diagram $Q$-factor as in [14].

For average optical received power levels above $-14 \mathrm{dBm}$, there is negligible penalty for transmission over $4 \mathrm{~km}$ of SMF compared to the back-to-back case, since the fiber dispersion is minimal relative to the UWB pulse width. Fig. 2(a) and (c) confirms that transmission does not significantly alter the pulse shape. Transmission over the $30 \mathrm{~km}$ of SMF with $5 \mathrm{~km}$ of matching DCF introduces a penalty of approximately $1.2 \mathrm{~dB}$ resulting from EDFA noise and chirp-to-intensity conversion during fiber propagation. The pulse shapes of Fig. 2(a) and (e) are once again very similar. Extrapolating the $781.25-\mathrm{Mb} / \mathrm{s}$ BER curves to a BER of $10^{-9}$ gives a receiver sensitivity of approximately $-9.5 \mathrm{dBm}$ for back-to-back and 4-km SMF transmission, and $-8.3 \mathrm{dBm}$ for transmission over $30 \mathrm{~km}$ of SMF.

\section{CONCLUSION}

The carrier dynamic response of an uncooled optically injected DFB laser was exploited to produce a $781.25-\mathrm{Mb} / \mathrm{s}$ UWB signal. The UWB signal was shown to be FCC-compliant. A DSP algorithm and 40-GSa/s digital storage oscilloscope were used to determine BER measurements for UWB signal transmission. The transmission penalty was found to be negligible for transmission over $4 \mathrm{~km}$ of SMF, and $1.2 \mathrm{~dB}$ for transmission over $30 \mathrm{~km}$ of SMF with $5 \mathrm{~km}$ of matching DCF. Simple optical UWB signal generation and distribution from a central office, along with the possible use of low-cost application specific integrated circuit DSP receiver chips pave the way for widespread cost-effective UWB communication networks.

\section{REFERENCES}

[1] D. Porcine, P. Research, and W. Hirt, "Ultra-wideband radio technology: Potential and challenges ahead," IEEE Commun. Mag., vol. 41, no. 7, pp. 66-74, Jul. 2003.

[2] J. Yao, F. Zeng, and Q. Wang, "Photonic generation of ultrawideband signals," J. Lightw. Technol., vol. 25, no. 11, pp. 3219-3235, Nov. 2007.

[3] C. Wang, F. Zeng, and J. P. Yao, "All-fiber ultrawideband pulse generation based on spectral shaping and dispersion-induced frequency-to-time conversion," IEEE Photon. Technol. Lett., vol. 19, no. 3, pp. 137-139, Feb. 1, 2007.

[4] Q. Wang and J. Yao, "An electrically switchable optical ultrawideband pulse generator," J. Lightw. Technol., vol. 25, no. 11, pp. 3626-3633, Nov. 2007.

[5] Q. Wang, F. Zeng, S. Blais, and J. Yao, "Optical ultrawideband monocycle pulse generation based on cross-gain modulation in a semiconductor optical amplifier," Opt. Lett., vol. 31, pp. 3083-3085, 2006.

[6] H. Chen, M. Chen, C. Qiu, and S. Xie, "A novel composite method for ultra-wideband doublet pulses generation," IEEE Photon. Technol. Lett., vol. 19, no. 24, pp. 2021-2023, Dec. 15, 2007.

[7] J. Li, S. Fu, K. Xu, J. Wu, J. Lin, M. Tang, and P. Shum, "Photonic ultrawideband monocycle pulse generation using a single electro-optic modulator," Opt. Lett., vol. 33, pp. 288-290, 2008.

[8] W. P. Lin and J. Y. Chen, "Implementation of a new ultrawide-band impulse system," IEEE Photon. Technol. Lett., vol. 17, no. 11, pp. 2418-2420, Nov., 2005.

[9] M. Abtahi, J. Magné, M. Mirshafiei, L. A. Rusch, and S. LaRochelle, "Generation of power-efficient FCC-compliant UWB waveforms using FBGs: Analysis and experiment," J. Lightw. Technol., vol. 26, no. 5, pp. 628-635, Mar. 1, 2008.

[10] Q. Wang and J. Yao, "UWB doublet generation using nonlinearly biased electro-optic intensity modulator," Electron. Lett., vol. 42, no. 22, pp. 1304-1305, 2006.

[11] T. Kawanishi, T. Sakamoto, and M. Izutsu, "Ultra-wide-band radio signal generation using optical frequency-shift-keying technique," IEEE Microw. Wireless Compon. Lett., vol. 15, no. 3, pp. 153-155, Mar. 2005

[12] V. Torres-Company, K. Prince, and I. T. Monroy, "Fiber transmission and generation of ultrawideband pulses by direct current modulation of semiconductor lasers and chirp-to-intensity conversion," Opt. Lett., vol. 33, pp. 222-224, 2008.

[13] T. B. Gibbon, X. Yu, D. Zibar, and I. T. Monroy, "Novel ultra-wideband photonic signal generation and transmission featuring digital signal processing bit error rate measurements," in OFC/NFOEC2009, CA, Mar. 2009, Paper OTuB8.

[14] R. Llorente, T. Alves, M. Morant, M. Beltran, J. Perez, A. Cartaxo, and J. Marti, "Ultra-wideband radio signals distribution in FTTH networks," IEEE Photon. Technol. Lett., vol. 20, no. 11, pp. 945-947, Jun. $1,2008$. 